\title{
Inhibition of Mild Steel Corrosion in Sulphuric Acid Using Esomeprazole and the Effect of Iodide Ion Addition
}

\author{
G. Karthik and M. Sundaravadivelu \\ Department of Chemistry, Gandhigram Rural Institute-Deemed University, Gandhigram, Tamil Nadu 624302, India
}

Correspondence should be addressed to M. Sundaravadivelu; msundar_gri@yahoo.com

Received 30 January 2013; Accepted 26 February 2013

Academic Editors: C. Bao, F. Deflorian, C. Gervasi, and E. M. Richter

Copyright ( $) 2013$ G. Karthik and M. Sundaravadivelu. This is an open access article distributed under the Creative Commons Attribution License, which permits unrestricted use, distribution, and reproduction in any medium, provided the original work is properly cited.

\begin{abstract}
The inhibition of the corrosion of mild steel in $1 \mathrm{M} \mathrm{H}_{2} \mathrm{SO}_{4}$ solution by the pharmaceutically active compound esomeprazole (ESP) has been investigated by using weight loss, potentiodynamic polarization, and electrochemical impedance spectroscopy measurements. The effect of temperature on the corrosion behavior with the addition of different concentrations of ESP was studied in the temperature range of $30-60^{\circ} \mathrm{C}$. Results obtained revealed that the inhibition efficiency increased with the increase in concentration of the inhibitor but decreased with the increase in temperature. The addition of KI increased the inhibition of ESP to a considerable extent. The experimental results suggest that the presence of iodide ions in the solution stabilized the adsorption of the ESP molecule on the mild steel surface, thereby improving the inhibition efficiency. Polarization curves indicated that the ESP belonged to a mixed-type inhibitor. Adsorption of the inhibitor on the mild steel surface is found to obey the Langmuir adsorption isotherm. Some thermodynamic functions of dissolution and adsorption processes were also determined. Surface analysis via scanning electron microscope (SEM) and atomic force microscope (AFM) shows a significant improvement in the surface morphology of the mild steel plate.
\end{abstract}

\section{Introduction}

The environmental consequence of corrosion is enormous, and its inhibition has been deeply investigated. It has been found that one of the best methods of protecting metals against corrosion involves the use of inhibitors which are substances that slow down the rate of corrosion [1]. Therefore, the development of corrosion inhibitors based on organic compounds containing nitrogen, sulphur, and oxygen atoms is of growing interest in the field of corrosion and industry [2]. The corrosion inhibition is a surface process, which involves adsorption of the organic compounds on a metal surface. The adsorption depends mainly on the electronic structure of the molecule [3]. The inhibition efficiency of organic compounds depends on the mode of interaction with the metal surface and molecular structure. However, there is an increasing concern about the toxicity of most corrosion inhibitors. The toxic effects not only affect living organisms but also poison the environment [4]. Due to the toxicity of some corrosion inhibitors, there has been increasing search for green corrosion inhibitors. Inhibitors in this class are those that are environmentally friendly and nontoxic.

Recently, several studies have been carried out on the inhibition of corrosion of metals by drugs. Moreover, the pharmaceutically active compound esomeprazole (ESP) is big enough (molecular mass $-345.417 \mathrm{~g} / \mathrm{mol}$ ) and likely to effectively cover more surface areas (due to adsorption) of the mild steel. Furthermore, ESP is very cheap, easily available, environmentally friendly, and, most importantly, nontoxic. In view of these favorable characteristics, ESP was chosen for the corrosion studies. The IUPAC name of ESP is [S]-5-methoxy-2-[(4-methoxy-3,5-dimethylpyridin2-yl)methylsulfinyl]-3H-benzoimidazole.

The main objective here is to find out the synergistic effect with halide ions and also to investigate the temperature dependence of the corrosion rate with the aim to obtain the apparent activation energies of the corrosion process of steel in $1 \mathrm{M} \mathrm{H}_{2} \mathrm{SO}_{4}$ solution in the absence and presence of different concentrations of ESP. It was also the purpose of the present work to test the experimental data with several 


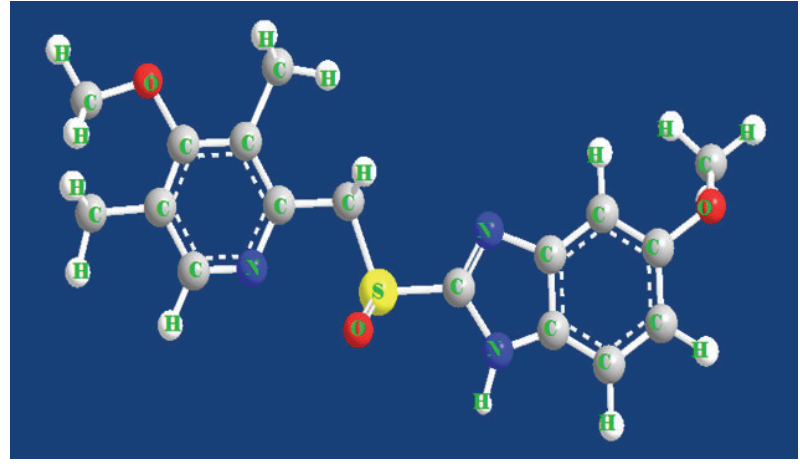

Figure 1: Structure of esomeprazole.

adsorption isotherms at different temperatures, in order to determine the standard free energies of the adsorption process and gain more information on the mode of adsorption of the inhibitor on the electrode surface.

\section{Experimental Technique}

Rectangular steel coupons in the size of $3.5 \times 1.5 \times 0.2 \mathrm{~cm}$ were cut with a small hole of $2 \mathrm{~mm}$ diameter at the upper edge of the specimen for weight loss studies. For the electrochemical studies, the size of the electrodes was $1 \mathrm{~cm}^{2}$ of exposed area with a $4 \mathrm{~cm}$ long tag for electrochemical contact. The mild steel sample used for the present study was analyzed in the IIT campus, Chennai, India and was found to have the composition (in wt.\%) $0.104 \% \mathrm{C}, 0.58 \% \mathrm{Mn}, 0.035 \% \mathrm{P}$, $0.026 \% \mathrm{~S}$, and the rest Fe. The corrosive solution was $1 \mathrm{M}$ $\mathrm{H}_{2} \mathrm{SO}_{4}$ obtained by dilution of sulphuric acid with triple distilled water. The ESP compound was separated from the drug (brand name Sompraz, Sun Pharma, Sikkim, India) by recrystallization with ethanol. The molecular structure of the used inhibitor is presented in Figure 1.

The inhibitor concentration in weight loss and electrochemical study was in the range 50-300 ppm. The test coupons were mechanically polished with different grades of emery papers $1 / 0,2 / 0,3 / 0,4 / 0,5 / 0$, and $6 / 0$, cleaned with acetone, washed with distilled water, and finally dried in dry air before every experiment. After weighing accurately, the specimens were immersed in $100 \mathrm{~mL}$ of $1 \mathrm{M} \mathrm{H}_{2} \mathrm{SO}_{4}$ with and without the addition of different concentrations of inhibitors. After $2 \mathrm{~h}$ of immersion the coupons were taken out, washed, dried, and weighed accurately. Duplicate experiments were performed in each, and the mean value of weight loss was reported. The corrosion rate $(\mathrm{CR})$ and the percentage of inhibition efficiency (IE\%) were calculated by the following equation:

$$
\operatorname{IE}(\%)=\left[\frac{W_{\mathrm{o}}-W_{i}}{W_{\mathrm{o}}}\right] \times 100,
$$

where $W_{0}$ is the corrosion rate in the absence of the inhibitor and $W_{i}$ is the corrosion rate in the presence of the inhibitor.

Two electrochemical techniques, namely, DC-Tafel slope and $\mathrm{AC}$ electrochemical impedance spectroscopy (EIS), were used to study the corrosion behavior. All electrochemical measurements were carried out using a CHI 760D electrochemical impedance analyzer model. For these studies a three-electrode cell assembly with $1 \mathrm{~cm}^{2}$ of mild steel as a working electrode, a saturated calomel electrode (SCE) as the reference electrode, and platinum foil as the counter electrode was used. The working electrode was polished before use. Before starting the electrochemical experiments, the test sample was allowed to reach steady-state value of OCP. The EIS measurements were carried out by using an ac signal of $0.1 \mathrm{~V}$ amplitude for the frequency spectrum from $100 \mathrm{kHz}$ to $0.01 \mathrm{~Hz}$ in the potential range $\pm 200 \mathrm{mV}$. The inhibition efficiency is calculated from the electrochemical impedance spectra by the following equation:

$$
\operatorname{IE}(\%)=\left[\frac{R_{\mathrm{ct}}^{i}-R_{\mathrm{ct}}^{\mathrm{o}}}{R_{\mathrm{ct}}^{i}}\right] \times 100,
$$

where $R_{\mathrm{ct}}^{i}$ and $R_{\mathrm{ct}}^{\mathrm{o}}$ are the charge transfer resistance values with and without esomeprazole, respectively. The inhibition efficiency is calculated from the polarization curves by the following equation:

$$
\mathrm{IE}(\%)=\left[\frac{I_{\text {corr }}^{\mathrm{o}}-I_{\text {corr }}^{i}}{I_{\text {corr }}^{\mathrm{o}}}\right] \times 100,
$$

where $I_{\text {corr }}^{\mathrm{o}}$ and $I_{\text {corr }}^{i}$ are the corrosion current densities in the absence and presence of inhibitor, respectively.

For the morphological study, surface features of carbon steel were examined after exposure to $1 \mathrm{M} \mathrm{H}_{2} \mathrm{SO}_{4}$ solutions in the absence and presence of the optimum concentration of ESP was examined by JEOL/EO JSM-6390 model scanning electron microscope (SEM) and atomic force microscopy model Nanosurf EZ2-AFM.

\section{Results and Discussion}

3.1. Weight Loss Measurements. Table 1 shows the results obtained from weight loss measurements for mild steel in $1 \mathrm{M} \mathrm{H}_{2} \mathrm{SO}_{4}$ solutions in the absence and presence of different concentrations of ESP. It has been observed from the results that the IE\% of ESP increases from $50.72 \%$ to $80.97 \%$ with the increase in inhibitor concentration from 50 to $300 \mathrm{ppm}$. Indeed, corrosion rate values of mild steel decreases from $107.1 \mathrm{mmy}^{-1}$ to $40.8 \mathrm{mmy}^{-1}$ on the addition of $50 \mathrm{ppm}$ to $300 \mathrm{ppm}$ of ESP. The increase in efficiency from $50.72 \%$ to $80.97 \%$ may be due to the blocking effect of the surface by both adsorption and film formation mechanisms, which decreases the effective area of corrosion attack [5]. The results confirm that ESP is an efficient corrosion inhibitor, which gives efficiency values as high as $80.97 \%$ in room temperature. The inhibiting performance exhibited by the compound may be due to the presence of protonated form of nitrogen and sulphur atoms of the compound which makes it adsorb quickly on the mild steel surface, thus forming an insoluble stable film on the surface of the mild steel. It is clear that ESP showed good inhibition for mild steel corrosion in $1 \mathrm{M}$ $\mathrm{H}_{2} \mathrm{SO}_{4}$ solutions because the inhibitor molecule is made of planar aromatic rings of benzoimidazole and a pyridine ring and also contains $\mathrm{S}$ and $\mathrm{N}$ atoms and $\pi$-electrons [6]. 
TABLE 1: Weight loss values of various concentrations of esomeprazole in $1 \mathrm{M} \mathrm{H}_{2} \mathrm{SO}_{4}$ solution.

\begin{tabular}{|c|c|c|c|c|}
\hline Concentration (ppm) & Weight loss $\left(\mathrm{mg} \mathrm{cm}^{-2}\right)$ & Corrosion rate $\left(\mathrm{mm} \mathrm{y}^{-1}\right)$ & Surface coverage $(\theta)$ & $\operatorname{IE} \eta(\%)$ \\
\hline blank & 184 & 657.1 & - & - \\
\hline 50 & 89 & 317.8 & 0.5072 & 50.72 \\
\hline 100 & 70 & 250 & 0.6195 & 61.95 \\
\hline 150 & 57 & 203.5 & 0.6903 & 69.03 \\
\hline 200 & 51 & 182.1 & 0.7229 & 72.29 \\
\hline 250 & 42 & 150 & 0.7716 & 77.17 \\
\hline 300 & 35 & 125 & 0.8097 & 80.97 \\
\hline
\end{tabular}

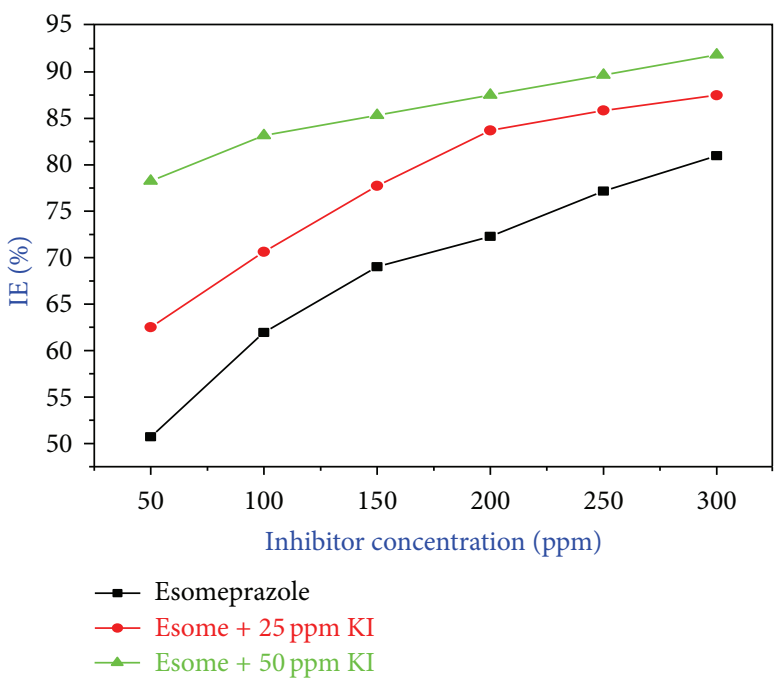

(a)

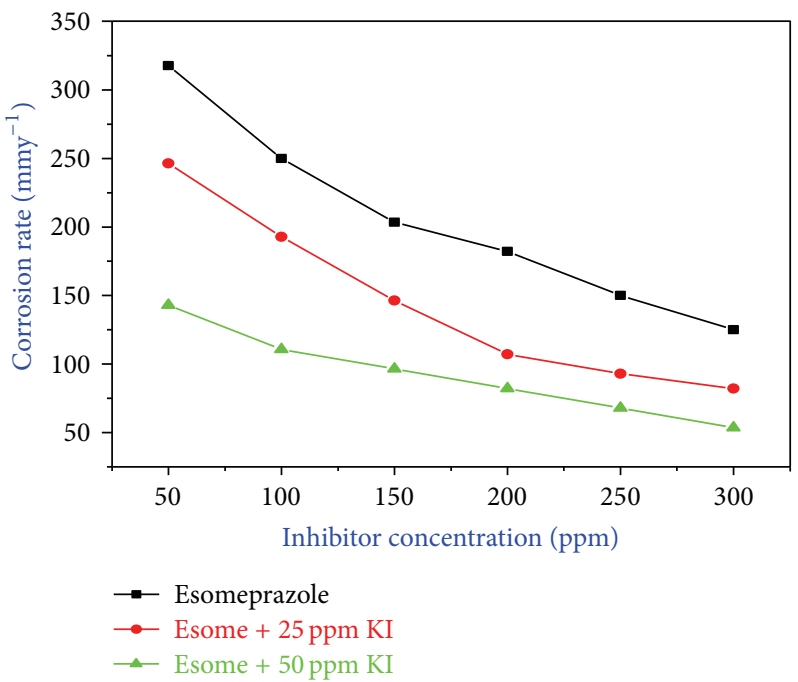

(b)

FIGURE 2: (a) Variation of corrosion rate in $1 \mathrm{M} \mathrm{H}_{2} \mathrm{SO}_{4}$ on mild steel with ESP with the addition of KI solution at room temperature, (b) variation of inhibition efficiency in $1 \mathrm{M} \mathrm{H}_{2} \mathrm{SO}_{4}$ on mild steel with $\mathrm{ESP}$ with the addition of $\mathrm{KI}$ solution at room temperature.

3.1.1. Synergistic Effect. Figures 2(a) and 2(b) show the values of corrosion rate (CR) and inhibition efficiency (IE\%) for various concentrations of ESP without and with the addition of 25 and $50 \mathrm{ppm}$ of potassium iodide. It is evident from the figure that the addition of KI decreases the corrosion rate and improves the inhibition efficiency of esomeprazole significantly. It is thought that the halide ions are able to improve adsorption of the organic cations by forming the intermediate bridges between the positively charged metal surface and the positive end of the inhibitor. The synergistic ability of the halide increases in the order $\mathrm{Cl}^{-}<\mathrm{Br}^{-}<$ $\mathrm{I}^{-}$[7] and is initiated by the specific adsorption of the anion onto the metal surface. The greater influence of the iodide ion is often attributed to its large ionic radius, high hydrophobicity, and low electronegativity compared to the other halide ions $[8,9]$. The synergistic effect between ESP and $\mathrm{I}^{-}$ions can be explained by the fact that the addition of the KI component stabilized the adsorption of ESP on mild steel surface $[10,11]$. This stabilization may be caused by the interaction between the ESP and $\mathrm{I}^{-}$ion. Thus, the interaction enhances the inhibition efficiency to a considerable extent due to the increase of the surface coverage in the presence of iodide ions.
3.1.2. Influence of Temperature. The loss in the weight of the steel samples in $1 \mathrm{M} \mathrm{H}_{2} \mathrm{SO}_{4}$ in the absence and presence of various concentrations of esomeprazole drug at different temperatures was determined. The effect of temperature on the inhibition efficiency of the ESP is shown in Table 2. In all cases, an increase in ESP concentration leads to a decrease in the corrosion rate of samples indicating that the presence of esomeprazole drug retards the general corrosion of samples in $1 \mathrm{M} \mathrm{H}_{2} \mathrm{SO}_{4}$. On the other hand, an increase in temperature from $303-333 \mathrm{~K}$ resulted in an increase in the corrosion rate for all the concentration of ESP, probably as a result of desorption of inhibitor molecules from the metal surface.

3.1.3. Adsorption Isotherm. The efficiency of the organic compound ESP as a corrosion inhibitor depends not only on the characteristics of the environment in which it acts, the nature of the metal surface and electrochemical potential at the interface, but also on the structure of the inhibitor itself, which includes the number of adsorption active centers in the molecule, their charge density, the molecule size, the mode of adsorption, the formation of metallic complexes, and the projected area of the inhibitor on the metallic surface [12]. The phenomenon of interaction between the metal surface and 
TABLE 2: Weight loss values of esomeprazole at various temperatures in $1 \mathrm{M} \mathrm{H}_{2} \mathrm{SO}_{4}$ solution.

\begin{tabular}{|c|c|c|c|c|c|c|c|c|}
\hline \multirow{2}{*}{ Concentration of inhibitor (ppm) } & \multicolumn{4}{|c|}{ Corrosion rate $\left(\mathrm{mm} \mathrm{y}^{-1}\right)$} & \multicolumn{4}{|c|}{ Inhibition efficiency (\%) } \\
\hline & $303 \mathrm{~K}$ & $313 \mathrm{~K}$ & $323 \mathrm{~K}$ & $333 \mathrm{~K}$ & $303 \mathrm{~K}$ & $313 \mathrm{~K}$ & $323 \mathrm{~K}$ & $333 \mathrm{~K}$ \\
\hline Blank & 657.1 & 659.7 & 735 & 821.5 & - & - & - & - \\
\hline 50 & 317.8 & 390.2 & 446 & 603 & 50.72 & 40.85 & 39.32 & 26.60 \\
\hline 100 & 250 & 289.1 & 318.2 & 444.2 & 61.95 & 56.18 & 41.68 & 45.93 \\
\hline 150 & 203.5 & 207.3 & 256.5 & 396.3 & 69.03 & 68.58 & 65.10 & 51.76 \\
\hline 200 & 182.1 & 180 & 223 & 320 & 72.29 & 72.71 & 69.65 & 61.05 \\
\hline 250 & 150 & 158.5 & 198.8 & 286.5 & 77.17 & 75.97 & 72.95 & 65.12 \\
\hline 300 & 125 & 127.2 & 180.1 & 241 & 80.97 & 80.71 & 75.50 & 70.66 \\
\hline
\end{tabular}

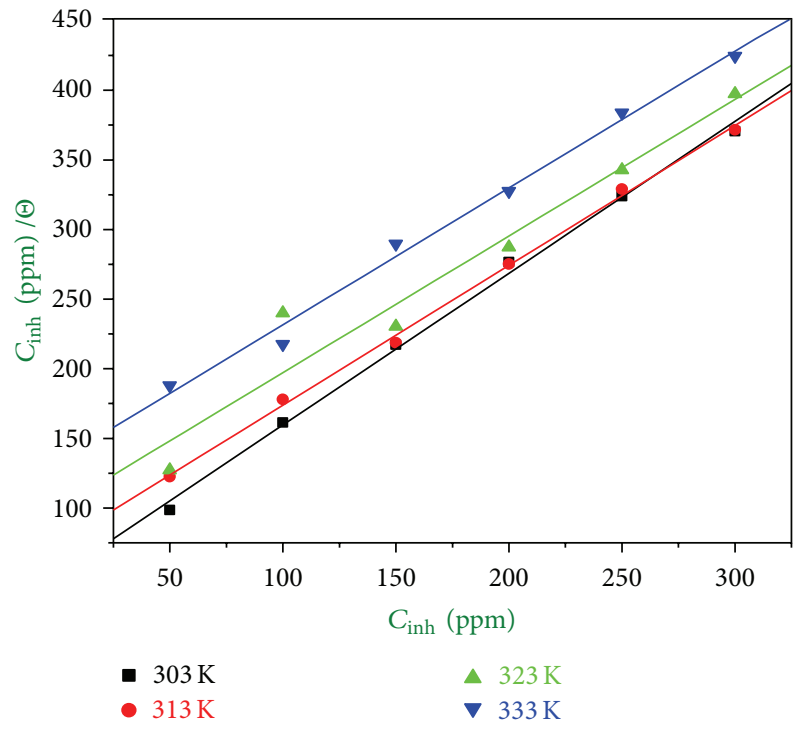

FIGURE 3: The langmuir adsorption isotherm plots for the adsorption of esomeprazole in $1 \mathrm{M} \mathrm{H}_{2} \mathrm{SO}_{4}$ on the surface of mild steel.

the inhibitor can be better understood in terms of adsorption isotherm. The plots of $C_{\text {inh }} / \theta$ against $C_{\text {inh }}$ (Figure 3 ) yield a straight line with approximately unit slope, indicating that the inhibitor under study obeys Langmuir adsorption isotherm. Assumptions of Langmuir relate the concentration of the adsorbate in the bulk of the electrolyte $\left(C_{\text {inh }}\right)$ to the degree of surface coverage $(\theta)$ as (5):

$$
\frac{C_{\mathrm{inh}}}{\theta}=\frac{1}{K_{\mathrm{ads}}}+C_{\mathrm{inh}},
$$

where $K_{\mathrm{ads}}$ is the equilibrium constant of adsorption and $\theta$ is the surface coverage and expressed by IE\%/100. By plotting values of $C_{\text {inh }} / \theta$ versus values of $C_{\text {inh }}$, straight line graphs were obtained (see Figure 3), which proves that the Langmuir adsorption isotherm is obeyed. Comparing the degree of linearity of the Langmuir adsorption isotherms as measured by values of $R^{2}$ (Table 3 ), it is seen that the Langmuir adsorption isotherm is best applicable at room temperature $(303 \mathrm{~K})$ than at higher temperatures. This confirms that the adsorption behavior of the inhibitor is strongly influenced by temperature. Also, values of the slope at room temperature $(303 \mathrm{~K})$ are greater than the values obtained at $313 \mathrm{~K}-333 \mathrm{~K}$,
TABLE 3: Thermodynamic adsorption parameters for mild steel in $1 \mathrm{M} \mathrm{H} \mathrm{H}_{2} \mathrm{SO}_{4}$ in the presence of optimum concentrations of esomeprazole at different temperatures.

\begin{tabular}{lccc}
\hline Temperature $(\mathrm{K})$ & $R^{2}$ & $K_{\mathrm{ads}}\left(10^{4} \mathrm{M}^{-1}\right)$ & $\Delta G_{\mathrm{ads}}^{\mathrm{o}}\left(\mathrm{KJ} \mathrm{mol}^{-1}\right)$ \\
\hline 303 & 0.9966 & 46.58 & -19.79 \\
313 & 0.9882 & 73.23 & -21.62 \\
323 & 0.9419 & 101.13 & -23.18 \\
333 & 0.9904 & 135.59 & -24.71 \\
\hline
\end{tabular}

indicating that the strength of the attractive behavior of the inhibitor decreases with temperature. The slope of the $C_{\mathrm{inh}} / \theta$ versus $C_{\text {inh }}$ plots shows deviation from unity, which means nonideal simulating [13] and being unexpected from the Langmuir adsorption isotherm. It might be the results from the interactions between the adsorbed species on the mild steel surface $[14,15]$. Adsorption equilibrium constant $\left(K_{\mathrm{ads}}\right)$ and free energy of adsorption $\left(\Delta G_{\text {ads }}^{o}\right)$ were calculated using the relationships:

$$
\Delta G_{\mathrm{ads}}^{\mathrm{o}}=-R T \ln \left(55.5 K_{\mathrm{ads}}\right)
$$

where 55.5 is the concentration of water in solution in $\mathrm{mol} \mathrm{L}^{-1}$ and $R$ is the universal gas constant. Calculated values of $\Delta G_{\text {ads }}^{o}$ and $K_{\text {ads }}$ were calculated from the plot of the isotherms in Figure 6 and recorded in Table 3. The $\Delta G_{\text {ads }}^{o}$ values are negative, and the values are $-19.79,-21.62,-23.18$, and $-24.71 \mathrm{~kJ} / \mathrm{mol}$ from $303 \mathrm{~K}$ to $333 \mathrm{~K}$, respectively, for the Langmuir isotherm plot. The negative values of $\Delta G_{\text {ads }}^{\mathrm{o}}$ ensure that the adsorption of the inhibitor molecule on to the steel surface is a spontaneous process. Generally, values of $\Delta G_{\text {ads }}^{o}$ up to $-20 \mathrm{~kJ} \mathrm{~mol}^{-1}$ are consistent with physisorption, while those around $-40 \mathrm{~kJ} \mathrm{~mol}^{-1}$ or higher values are associated with chemisorption as a result of the sharing or transfer of electrons from organic molecules to the metal surface to form a coordinate type of metal bonds [16]. In the present study, the calculated values of $\Delta G_{\text {ads }}^{o}$ range between -19.79 and $-24.71 \mathrm{~kJ} \mathrm{~mol}^{-1}$ (Table 3), indicating that the adsorption mechanism of ESP on mild steel in $1 \mathrm{M} \mathrm{H}_{2} \mathrm{SO}_{4}$ solution at the studied temperatures may be a combination of both physisorption and chemisorption (comprehensive adsorption). However, physisorption was the major contributor, while chemisorption only slightly contributed to the 


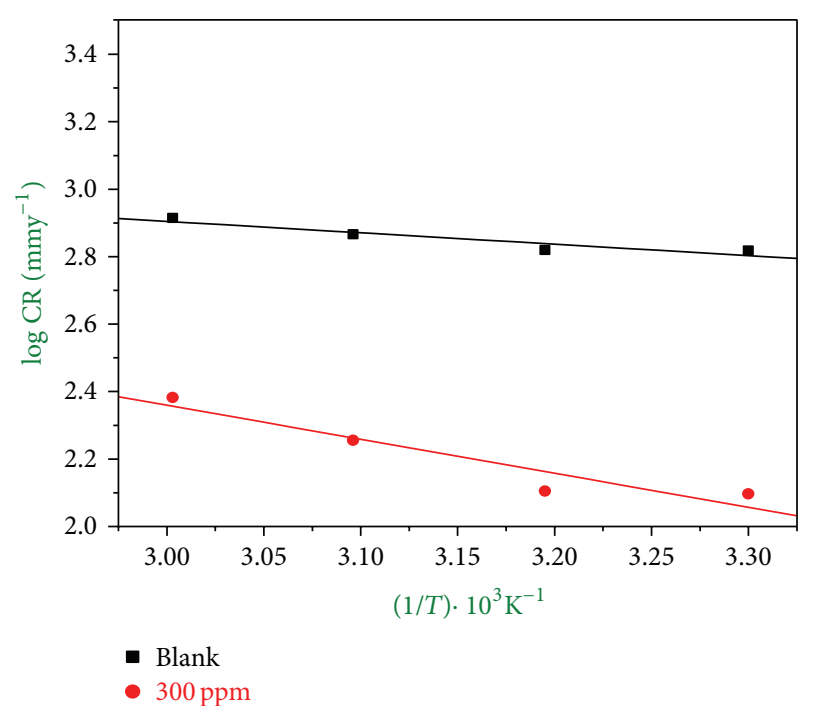

(a)

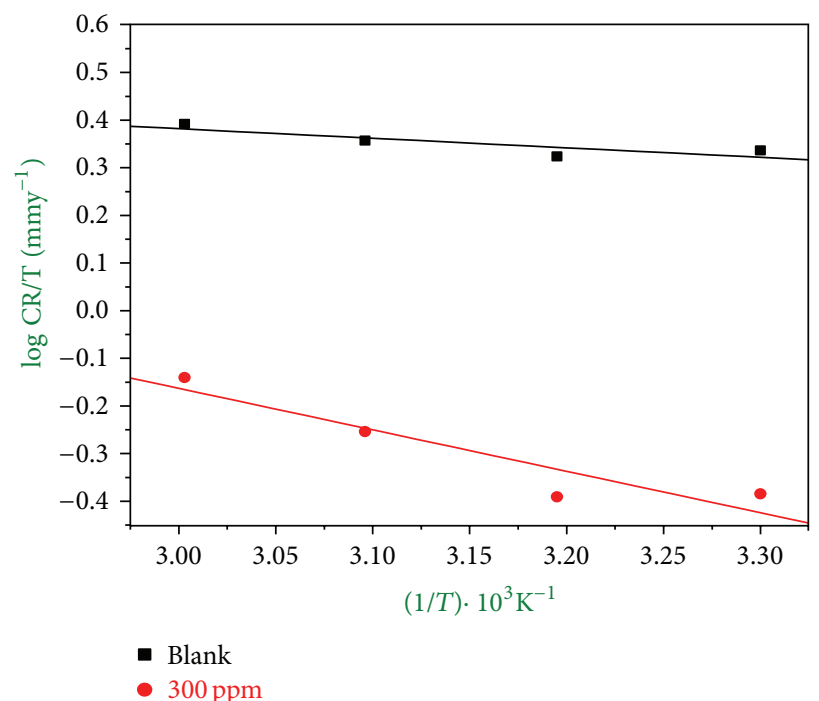

(b)

Figure 4: (a) Adsorption isotherm plots for log CR versus 1/T. (b) Adsorption isotherm plot for $\log C R / T$ versus $1 / T$.

TABLE 4: Thermodynamic activation parameters for mild steel in $1 \mathrm{M}$ $\mathrm{H}_{2} \mathrm{SO}_{4}$ in the absence and presence of different concentrations of esomeprazole.

\begin{tabular}{lccc}
\hline $\begin{array}{l}\text { Concentration of } \\
\text { Inhibitor }(\mathrm{ppm})\end{array}$ & $E_{a}^{\mathrm{o}}\left(\mathrm{KJ} \mathrm{mol}^{-1}\right)$ & $\begin{array}{c}-\Delta H_{a}^{\mathrm{o}} \\
\left(\mathrm{KJ} \mathrm{mol}^{-1}\right)\end{array}$ & $\begin{array}{c}-\Delta S_{a}^{\mathrm{o}} \\
\left(\mathrm{KJ} \mathrm{mol}^{-1}\right)\end{array}$ \\
\hline $1 \mathrm{M} \mathrm{H}_{2} \mathrm{SO}_{4}$ & 75.05 & 18.837 & 201.45 \\
$300 \mathrm{ppm}$ & 103.1 & 46.879 & 214.28 \\
\hline
\end{tabular}

adsorption mechanism judging from the decrease of IE \% with increase in temperature.

3.1.4. Thermodynamic Parameters. Thermodynamic parameters are important to understand the inhibition mechanism. The thermodynamic functions for dissolution of mild steel without and with the addition of optimum concentration of ESP at various temperatures were calculated from the logarithm of corrosion rate (CR) of metal in acidic $\mathrm{H}_{2} \mathrm{SO}_{4}$ solution by using the Arrhenius equation:

$$
\log \mathrm{CR}=\frac{-E_{a}^{\mathrm{o}}}{2.303 R T}+A,
$$

where $\mathrm{CR}$ is the corrosion rate, $E_{a}^{o}$ is the apparent activation energy, and $A$ is the preexponential factor. The arrhenius plots of log CR versus $1 / T$ for the blank and different concentrations of ESP give a straight line and a slope equal to $-\left(E_{a}^{\mathrm{o}} / 2.303 R\right)$ shown in Figure 4 , from which the values of $E_{a}^{o}$ for the inhibited corrosion reaction of mild steel have been calculated and recorded in Table 4 . It was observed for the $\mathrm{H}_{2} \mathrm{SO}_{4}$ solution that $E_{a}^{\mathrm{o}}, 75.05 \mathrm{~kJ} \mathrm{~mol}^{-1}$. In the presence of the inhibitor is the activation energies are increased up to $103.1 \mathrm{~kJ} \mathrm{~mol}^{-1}$ compared to the acid solution revealing the retardation of the corrosion reaction. The marked changes in $E_{a}^{o}$ suggest that the inhibitor may either participate in the electrode or may change the potential difference of the metal-solution interface by adsorption.

From the transition state equation:

$$
\mathrm{CR}=\frac{R T}{N h} \exp \left(\frac{\Delta S_{a}^{\mathrm{o}}}{R}\right) \exp \left(-\frac{\Delta H_{a}^{\mathrm{o}}}{R T}\right),
$$

where $\Delta H_{a}^{\mathrm{o}}$ is the enthalpy of activation, $\Delta S_{a}^{\mathrm{o}}$ is the entropy of activation, $h$ is Planck's constant, $N$ is the Avogadro number, and $R$ is the universal gas constant, the plot of log $(\mathrm{CR} / T)$ versus $1 / T$ gives straight lines with a slope equal to $-\left(\Delta H_{a}^{\mathrm{o}} / 2.303 R\right)$ and an intercept $\left(\log (R / N h)+\left(\Delta S_{a}^{\mathrm{o}} / 2.303 R\right)\right)$ from which $\Delta H_{a}^{\mathrm{o}}$ and $\Delta S_{a}^{\mathrm{o}}$ values were calculated and listed in Table 4. The negative sign of $\Delta H_{a}^{\mathrm{o}}$ indicates that the adsorption process is exothermic [17]. This indicates that IE \% decreases when the temperature increases. Such behavior can be interpreted on the basis that increasing the temperature resulted in desorption of the adsorbed inhibitor molecules from the metal surface. The negative values of $\Delta S_{a}^{o}$ might be explained in the following way: before the adsorption of inhibitors onto the metal surface, inhibitor molecules might freely move in the bulk solution, but with the progress in the adsorption, inhibitor molecules were orderly adsorbed onto the metal surface, and as a result, there was a decrease in entropy [18].

3.2. Electrochemical Impedance Spectroscopy. The corrosion behavior of mild steel in $1 \mathrm{M} \mathrm{H}_{2} \mathrm{SO}_{4}$ with different concentrations of ESP and its synergistic effect with potassium iodide solution were studied by AC impedance spectroscopy. In general, the impedance spectra exhibit one single depressed semicircle, and the diameter of the semicircle increases with the increase of inhibitor concentration. The semicircle can be attributed to the charge transfer that takes place at electrode/solution interface, and the transfer process controls the corrosion reaction of mild steel. The existence of a single 


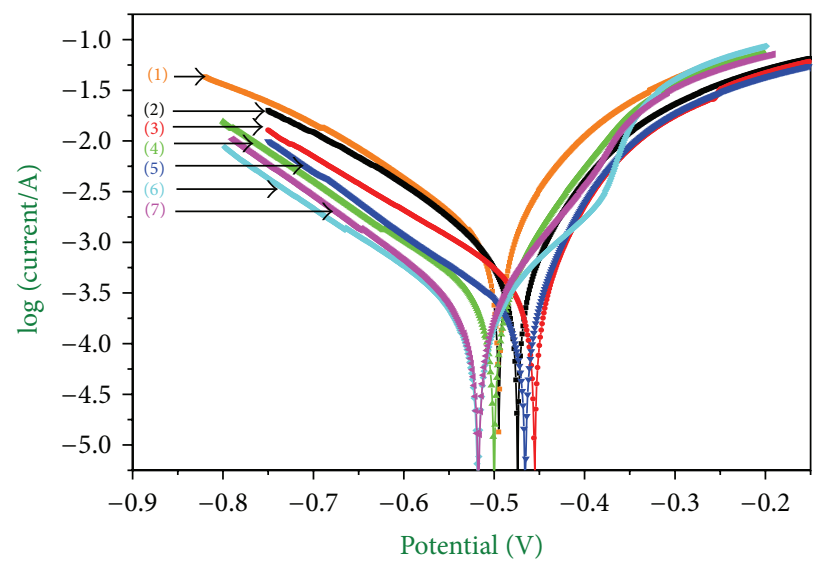
(1) Blank
(2) $50 \mathrm{ppm}$
(3) $100 \mathrm{ppm}$
(4) $150 \mathrm{ppm}$

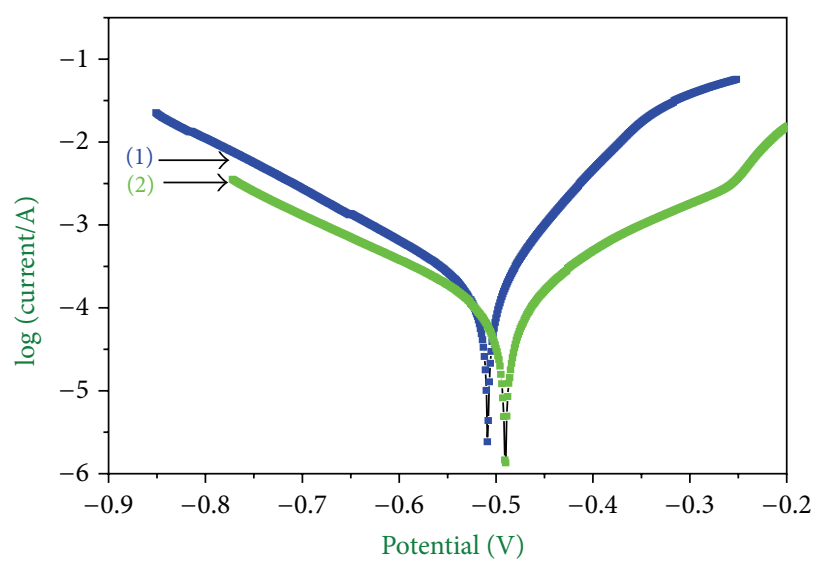

(1) $25 \mathrm{ppm} \mathrm{KI}$ (2) 50 ppm KI

(a)

(b)

Figure 5: (a) Nyquist plots of mild steel in $1 \mathrm{M} \mathrm{H}_{2} \mathrm{SO}_{4}$ with various concentrations of esomeprazole. (b) Nyquist plots of mild steel in $1 \mathrm{M}$ $\mathrm{H}_{2} \mathrm{SO}_{4}$ with various concentrations of esomeprazole with the addition of KI.

TABLE 5: Electrochemical impedance parameters for mild steel in $1 \mathrm{M} \mathrm{H}_{2} \mathrm{SO}_{4}$ containing different concentrations of esomeprazole with the addition of KI.

\begin{tabular}{lccc}
\hline $\begin{array}{l}\text { Inhibitor } \\
\text { concentration } \\
(\mathrm{ppm})\end{array}$ & $R_{\mathrm{Ct}}\left(\Omega \mathrm{cm}^{2}\right)$ & $C_{\mathrm{dl}}\left(\mu \mathrm{F} \mathrm{cm}^{-2}\right)$ & I.E $\eta(\%)$ \\
\hline Blank & 13.67 & 1656.9 & - \\
50 & 44.746 & 153.8 & 69.45 \\
100 & 48.623 & 134.58 & 71.89 \\
150 & 53.798 & 110.93 & 74.59 \\
200 & 56.90 & 96.86 & 75.98 \\
250 & 59.582 & 87.18 & 77.06 \\
300 & 66.291 & 71.77 & 79.38 \\
$25 \mathrm{ppm} \mathrm{KI}$ & 68.499 & 66.6 & 80.04 \\
$50 \mathrm{ppm} \mathrm{KI}$ & 86.567 & 41.83 & 84.21 \\
\hline
\end{tabular}

semicircle shows the single charge transfer process during dissolution which is unaffected by the presence of inhibitor molecules $[19,20]$. The impedance spectra observed are depicted in Figure 5. In the diagrams, imaginary component $Z^{\prime \prime}$ was plotted against real component $Z^{\prime}$. It indicates that the mechanism of mild steel corrosion in the absence and presence of ESP is purely controlled by the charge transfer process. It is also observed that the $R_{\mathrm{ct}}$ values of mild steel in $1 \mathrm{M} \mathrm{H}_{2} \mathrm{SO}_{4}$ with different concentrations of ESP are higher than the uninhibited solution. The impedance parameters obtained from the curves are given in Table 5.

Inspection of the results in Table 5 indicated that the charge transfer resistance increased with an increase in the concentration of ESP and KI. The change of $R_{\mathrm{ct}}$ values can be related to the gradual replacement of water molecules and/or hydroxyl ions by ESP molecule on the surface and consequently leads to a decrease in the number of active sites necessary for the corrosion reaction. The increase in $R_{\mathrm{ct}}$ value is attributed to the formation of a protective film on the metal/solution interface. Moreover, the values of double-layer capacitance, $C_{\mathrm{dl}}$, decreased with increasing ESP concentration. The decrease in $C_{\mathrm{dl}}$ is probably due to a decrease in local dielectric constant and/or an increase in the thickness of a protective layer at electrode surface, enhancing therefore the corrosion resistance of the studied steel. The interfacial double-layer capacitance $\left(C_{\mathrm{dl}}\right)$ values have been estimated from the impedance value using the Nyquist plot by the formula

$$
C_{\mathrm{dl}}=\left(2 \pi f_{\max } R_{\mathrm{ct}}\right)^{-1} .
$$

The maximum inhibition efficiency $(79.38 \%)$ is obtained for $300 \mathrm{ppm}$ of ESP, and the inhibition efficiency is increased (84.21) when adding $50 \mathrm{ppm}$ of KI solution. The values of AC impedance corroborates the results obtained from weight loss and polarization studies.

3.3. Tafel Polarization. Potentiodynamic polarization curves for mild steel in $1 \mathrm{M} \mathrm{H}_{2} \mathrm{SO}_{4}$ with and without ESP with shown in Figures 6(a) and 6(b). The important parameters of corrosion current densities $\left(I_{\text {corr }}\right)$, cathodic Tafel slope $\left(\beta_{c}\right)$, anodic Tafel slope $\left(\beta_{\mathrm{a}}\right)$, and the inhibition efficiency (IE \%) as functions of ESP concentrations are derived from polarization curves that are presented in Table 6. From Table 6, it is clear that the corrosion current density $\left(I_{\text {corr }}\right)$ values decreases from $1.4060 \mathrm{mAcm}^{-2}$ to $0.2142 \mathrm{mAcm}^{-2}$ and $0.1120 \mathrm{mAcm}^{-2}$ with the addition of optimum concentration $(300 \mathrm{ppm})$ of ESP and ESP with $50 \mathrm{ppm}$ of KI, respectively. The cathodic and anodic Tafel slope values are almost the same with and without inhibitors. It conforms that esomeprazole adsorbs on metal surfaces by simply blocking the active sites, and the 

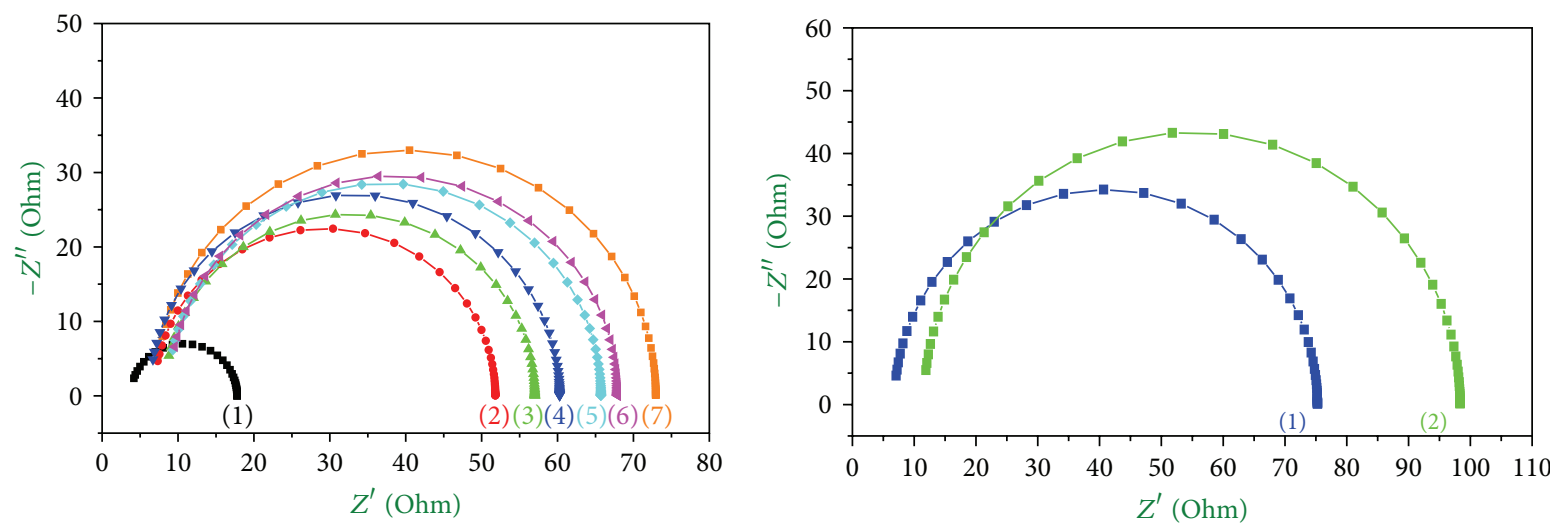

(1) Blank
(2) $50 \mathrm{ppm}$
(3) $100 \mathrm{ppm}$
(4) $150 \mathrm{ppm}$

(5) $200 \mathrm{ppm}$

(6) $250 \mathrm{ppm}$

(7) $300 \mathrm{ppm}$

(1) $25 \mathrm{ppm} \mathrm{KI}$

(2) $50 \mathrm{ppm} \mathrm{KI}$

(a)

(b)

Figure 6: Tafel polarization behavior of mild steel in (a) $1 \mathrm{M} \mathrm{H}_{2} \mathrm{SO}_{4}$ with different concentrations of esomeprazole and (b) $1 \mathrm{M} \mathrm{H}_{2} \mathrm{SO}_{4}$ with different concentrations of esomeprazole with the addition of KI.

TABLE 6: Tafel polarization for the corrosion of mild steel in $1 \mathrm{M} \mathrm{H}_{2} \mathrm{SO}_{4}$ in the absence and presence of different concentrations of esomeprazole with the addition of KI.

\begin{tabular}{|c|c|c|c|c|c|c|}
\hline Inhibitor concentration (ppm) & $\beta_{\mathrm{a}}(\mathrm{mV})$ & $\beta_{\mathrm{c}}(\mathrm{mV})$ & $-E_{\text {corr }}(\mathrm{mV} / \mathrm{SCE})$ & $I_{\text {corr }}\left(\mathrm{mA} / \mathrm{cm}^{2}\right)$ & Linear polarization $(R)$ & IE (\%) \\
\hline Blank & 8.6330 & 6.463 & 494.2 & 1.4060 & 20.5 & - \\
\hline 50 & 10.168 & 6.951 & 473.9 & 0.6035 & 42.1 & 57.08 \\
\hline 100 & 9.9790 & 5.516 & 454.9 & 0.4942 & 56.8 & 64.85 \\
\hline 150 & 11.854 & 5.897 & 502.3 & 0.3493 & 70.1 & 75.16 \\
\hline 200 & 11.232 & 5.891 & 465.1 & 0.2826 & 89.9 & 79.90 \\
\hline 250 & 8.0010 & 6.316 & 516.4 & 0.2264 & 134.1 & 83.90 \\
\hline 300 & 10.955 & 6.847 & 517.8 & 0.2142 & 114 & 84.76 \\
\hline 25 ppm KI & 13.094 & 6.757 & 508.1 & 0.1778 & 122.5 & 87.35 \\
\hline 50 ppm KI & 7.5050 & 5.898 & 490.0 & 0.1120 & 289.7 & 92.03 \\
\hline
\end{tabular}

mechanisms of anodic and cathodic reactions are unaffected [21]. The shift of the corrosion potential $\left(E_{\text {corr }}\right)$ shows a slight shift towards the cathodic side region as concentrations of the inhibitor increased from 50 to $300 \mathrm{ppm}$, suggesting that the effect of the inhibitor is more pronounced at the cathodic side. However, according to Ferreira and others $[7,22]$ if the displacement in corrosion potential is more than $85 \mathrm{mV}$ with respect to the corrosion potential of the uninhibited solution, the inhibitor can be seen as a cathodic or anodic type. In the present study, the maximum displacement was $23 \mathrm{mV}$, indicating that ESP belonged to mixed type. These results suggest that the studied inhibitor was first adsorbed onto the metal surface and impeded by merely blocking the metal surface without affecting the anodic and cathodic reaction mechanism [23].

3.4. Scanning Electron Microscopy. The SEM images were recorded (Figures $7(\mathrm{a}), 7(\mathrm{~b}), 7(\mathrm{c})$, and $7(\mathrm{~d})$ ) to establish the interaction of inhibitor molecules with the metal surface. The SEM images show the features of mild steel surface after $2 \mathrm{~h}$ in $1 \mathrm{M} \mathrm{H}_{2} \mathrm{SO}_{4}$ in absence and presence of optimum concentration of esomeprazole (300 ppm) (Figure 7(c)) and adding $50 \mathrm{ppm}$ of KI solution (Figure 7(d)) at room temperature. The SEM images revealed that the mild steel specimen immersed in inhibited solutions (Figures $7(\mathrm{c})$ and $7(\mathrm{~d})$ ) is in better conditions having smooth productive film coating, while the metal surface immersed in blank acid solutions (Figure 7(b)) is roughly covered with corrosion products and appeared to be full of pits and cavities. The polishing stretches are also visible on the surface in Figure 7(a). This indicated that the ESP molecules hinder the dissolution of iron by forming protective film on mild steel surface and thereby reduce the corrosion rate. The surface analysis results suggest higher adsorption of ESP on the surface of mild steel, which support the weight loss, EIS, and polarization results.

3.5. Atomic Force Microscopy. An atomic force microscope (AFM) was used to image the mild steel specimen, and it was used mainly for measuring three-dimensional topography. Analysis of the images allowed quantification of surface roughness over area scales $2 \mu \mathrm{m} \times 2 \mu \mathrm{m}$. The three dimensional AFM images are shown in Figures 8(a)-8(c). As can 


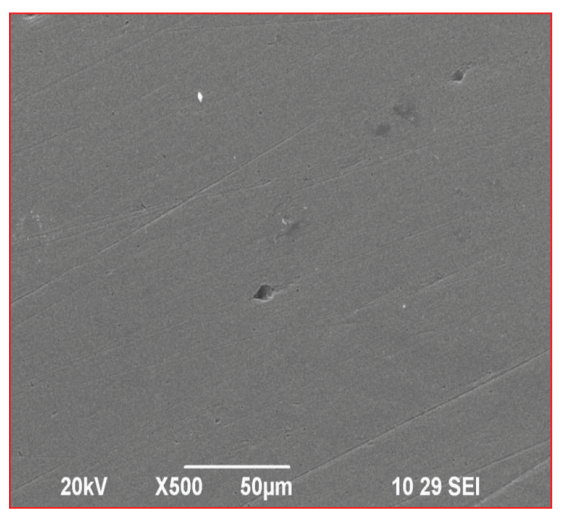

(a)

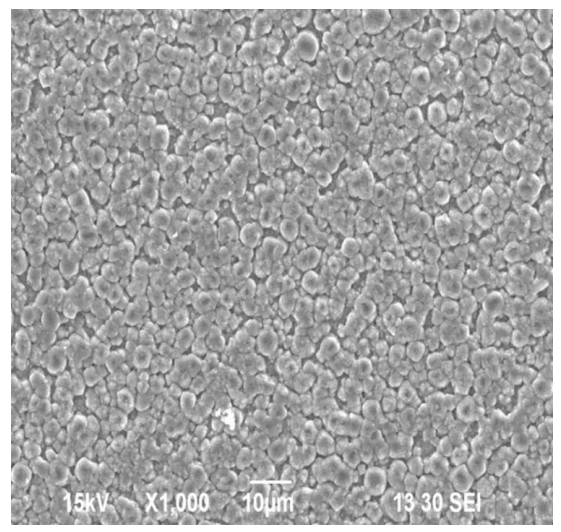

(c)

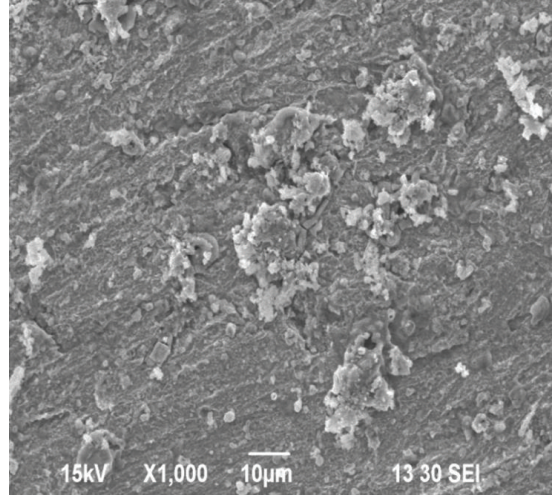

(b)

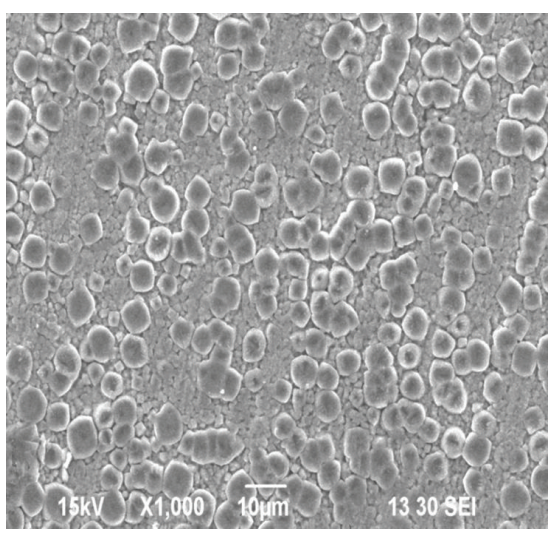

(d)

FIGURE 7: SEM images of mild steel: (a) polished metal, (b) $1 \mathrm{M} \mathrm{H}_{2} \mathrm{SO}_{4}$ solution without esomeprazole, (c) $0.5 \mathrm{M} \mathrm{H}_{2} \mathrm{SO}_{4}$ solution with optimum concentration of esomeprazole, and (d) $1 \mathrm{M} \mathrm{H}_{2} \mathrm{SO}_{4}$ solution with optimum concentration of esomeprazole + KI.

be seen from Figures $8(a)-8(\mathrm{c})$, the average roughness of polished mild steel (Figure 8(a)) and mild steel in $1 \mathrm{M} \mathrm{H}_{2} \mathrm{SO}_{4}$ without inhibitor (Figure 8(b)) was calculated to be $759 \mathrm{~nm}$ and $129 \mathrm{~nm}$, respectively. The mild steel surface in the free acid solution is getting cracked due to the acid attack on the surface (Figure 8(b)). However, in the presence of $300 \mathrm{ppm}$ concentration of esomeprazole drug, the average roughness was reduced to $276 \mathrm{~nm}$ (Figure 8(c)).

\section{Inhibition Mechanism}

The ESP can be easily protonated in the sulphuric acid solution because the molecule is made of a planer of benzoimidazole, pyridine ring, and also contains $\mathrm{S}, \mathrm{N}$, and $\mathrm{O}$ atoms with lone pair electrons and $\pi$ electrons. Thus, they become cations, existing in equilibrium with the corresponding molecular form

$$
\mathrm{ESP}+x \mathrm{H}^{+} \longleftrightarrow\left[\mathrm{ESPH}_{x}\right]^{x+}
$$

Physical adsorption may take place due to electrostatic interaction between protonated molecule and $\mathrm{FeSO}_{4}^{2-}$ species. Coordinate covalent bond formation between electron pairs of unprotonated $\mathrm{S}$ atom and $\mathrm{N}$ atoms of aromatic rings with metal surface can take place [24]. In addition, ESP molecules are chemically adsorbed due to the interaction of $\pi$-orbitals with metal surface. This phenomenon is associated with the deprotonation of physically adsorbed protonated molecules. In the present study, the value of $\Delta G_{\mathrm{ads}}^{\mathrm{o}}$ is from $-19.79 \mathrm{~kJ} \mathrm{~mol}^{-1}$ to $-24.71 \mathrm{~kJ} \mathrm{~mol}^{-1}$, hence, showing that adsorption of ESP molecules on the surface of mild steel takes place through both physical as well as chemical processes.

\section{Conclusion}

(i) Esomeprazole acts as a good inhibitor for the corrosion of mild steel in $1 \mathrm{M} \mathrm{H}_{2} \mathrm{SO}_{4}$.

(ii) The inhibition efficiency and corrosion rate of esomeprazole increased with adding potassium iodide and decreased with temperature.

(iii) The EIS measurements suggest that ESP molecules function by adsorption at metal surface thereby causing the decrease in $C_{\mathrm{dl}}$ values and increasing in $R_{\mathrm{ct}}$ values.

(iv) Potentiodynamic polarization curve reveals that ESP belonged to mixed-type inhibitor, and the effect of the inhibitor is more pronounced at the cathodic side.

(v) The adsorption of ESP obeys the Langmuir adsorption isotherm. The adsorption process is a 


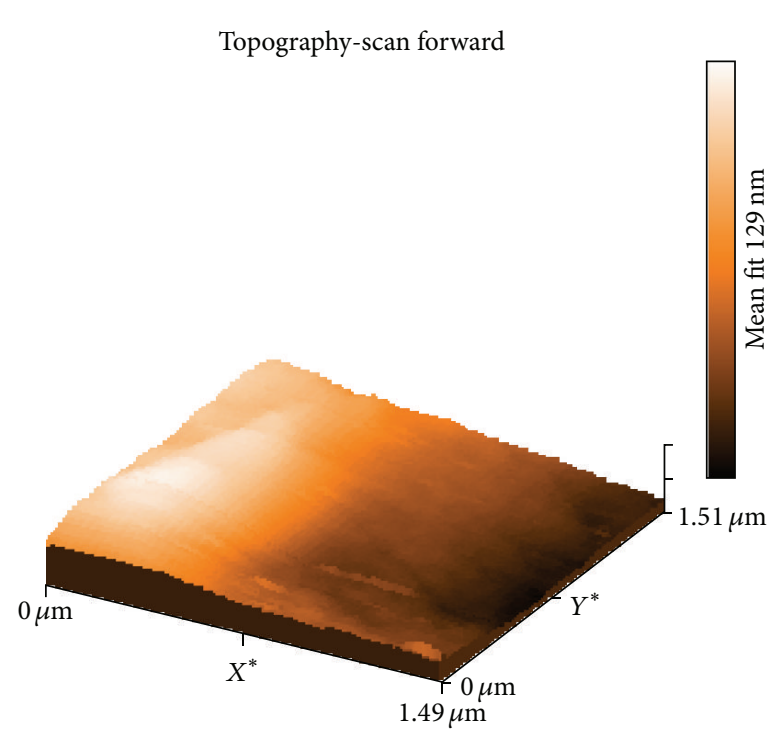

(a)

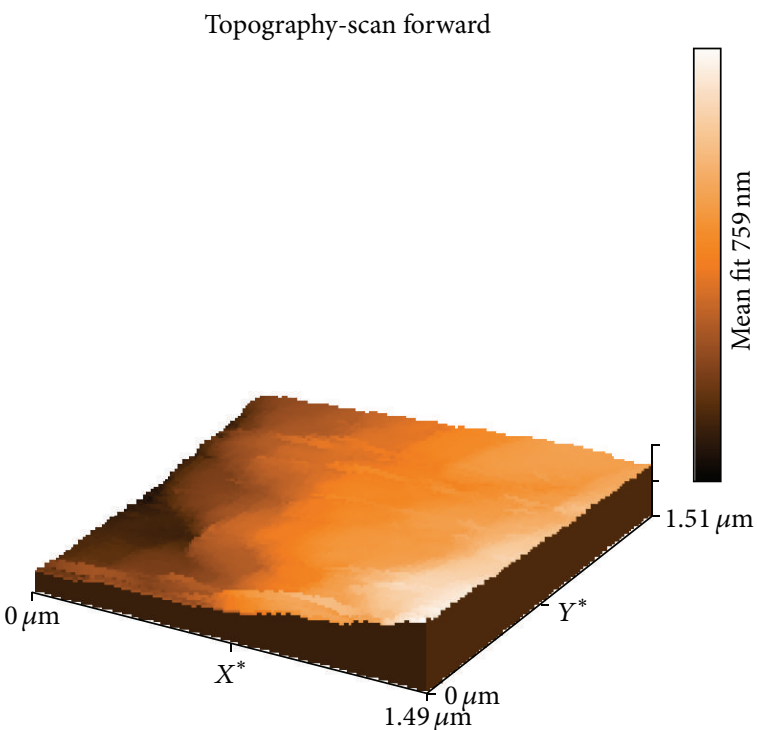

(b)

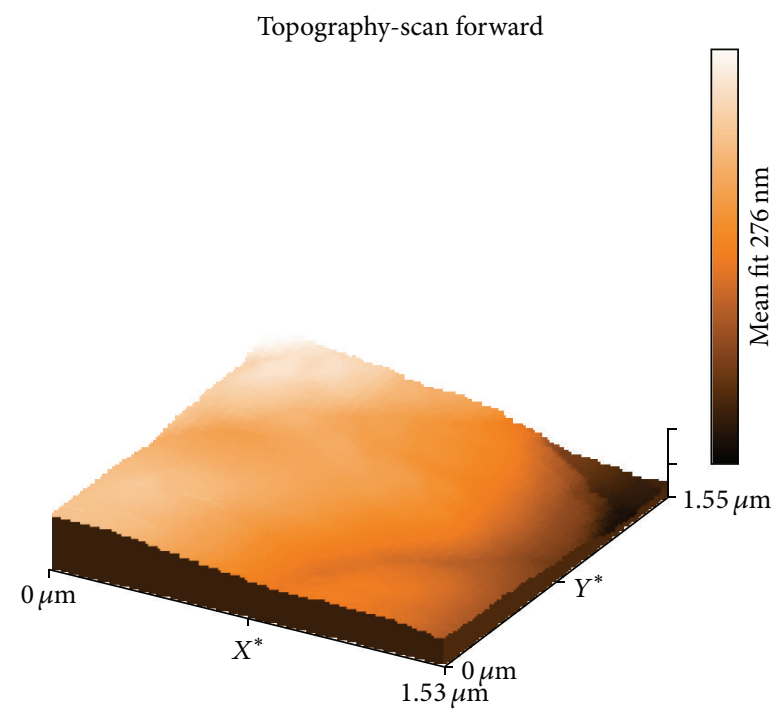

(c)

FIGURE 8: AFM images of mild steel: (a) polished metal, (b) $1 \mathrm{M} \mathrm{H}_{2} \mathrm{SO}_{4}$ solution without esomeprazole, and (c) $1 \mathrm{M} \mathrm{H}_{2} \mathrm{SO}_{4}$ solution with optimum concentration of esomeprazole.

spontaneous and exothermic process accompanied by an increase of entropy.

(vi) The surface analysis indicated that the ESP molecules hinder the dissolution of iron by forming protective film on mild steel surface and thereby reduce the corrosion rate.

(vii) The results obtained from weight loss, impedance, and polarization studies are in good agreement.

\section{Acknowledgments}

All the authors are thankful to UGC-SAP, and one of the authors, G. Karthik, is grateful to the UGC for the fellowship under Research Fellowship in Sciences for Meritorious Students.

\section{References}

[1] S. A. Ali, M. T. Saeed, and S. V. Rahman, “The isoxazolidines: a new class of corrosion inhibitors of mild steel in acidic medium," Corrosion Science, vol. 45, no. 2, pp. 253-266, 2003.

[2] F. Bentiss, M. Lagrence, M. Traisnel, and J. C. Hornez, "The corrosion inhibition of mild steel in acidic media by a new triazole derivative," Corrosion Science, vol. 41, no. 4, pp. 789803, 1999.

[3] M. A. Quraishi, R. Sardar, and D. Jamal, "Corrosion inhibition of mild steel in hydrochloric acid by some aromatic hydrazides," Materials Chemistry and Physics, vol. 71, no. 3, pp. 309-313, 2001.

[4] R. A. Prabhu, A. V. Shanbhag, and T. V. Venkatesha, "Influence of tramadol [2-[(dimethylamino)methyl]-1-(3-methoxyphenyl) cyclohexanol hydrate] on corrosion inhibition of mild steel in acidic media," Journal of Applied Electrochemistry, vol. 37, no. 4, pp. 491-497, 2007. 
[5] T. P. Zhao and G. N. Mu, "The adsorption and corrosion inhibition of anion surfactants on aluminium surface in hydrochloric acid," Corrosion Science, vol. 41, no. 10, pp. 1937-1944, 1999.

[6] I. . Ahamed and M. A. Quraishi, "Mebendazole: new and efficient corrosion inhibitor for mild steel in acid medium," Corrosion Science, vol. 52, no. 2, pp. 651-656, 2010.

[7] W.-h. Li, Q. He, S.-t. Zhang, C. 1. Pei, and B.-r. Hou, "Some new triazole derivatives as inhibitors for mild steel corrosion in acidic medium," Journal of Applied Electrochemistry, vol. 38, no. 3, pp. 289-295, 2008.

[8] S. A. Umoren and E. E. Ebenso, "The synergistic effect of polyacrylamide and iodide ions on the corrosion inhibition of mild steel in $\mathrm{H}_{2} \mathrm{SO}_{4}$," Materials Chemistry and Physics, vol. 106, no. 2-3, pp. 387-393, 2007.

[9] R. T. Foley, "Role of the chloride ion in iron corrosion," Corrosion, vol. 26, no. 2, pp. 58-70, 1970.

[10] M. A. Quraishi and J. Rawat, "Corrosion inhibition of mild steel in acid solutions by tetramethyl-dithia-octaazacyclotetradeca hexaene (MTAT)," Anti-Corrosion Methods and Materials, vol. 47, no. 5, pp. 288-293, 2000.

[11] S. Khan and M. A. Quraishi, "Synergistic effect of potassium iodide on inhibitive performance of thiadiazoles during corrosion of mild steel in 20\% sulfuric acid," The Arabian Journal For Science and Engineering, vol. 35, no. 1A, pp. 71-82, 2010.

[12] L. M. Vracar and D. M. Drazic, "Adsorption and corrosion inhibitive properties of some organic molecules on iron electrode in sulfuric acid," Corrosion Science, vol. 44, no. 8, pp. 1669 1680, 2002.

[13] W. A. Badawy, K. M. Ismail, and A. M. Fathi, "Corrosion control of $\mathrm{Cu}-\mathrm{Ni}$ alloys in neutral chloride solutions by amino acids," Electrochimica Acta, vol. 51, no. 20, pp. 4182-4189, 2006.

[14] M. A. Migahed, H. M. Mohammed, and A. M. Al-Sabagh, "Corrosion inhibition of $\mathrm{H}-11$ type carbon steel in $1 \mathrm{M}$ hydrochloric acid solution by $N$-propyl amino lauryl amide and its ethoxylated derivatives," Materials Chemistry and Physics, vol. 80, no. 1, pp. 169-175, 2003.

[15] A. A. Abdul Azim, L. A. Shalaby, and H. Abbas, "Mechanism of the corrosion inhibition of $\mathrm{Zn}$ Anode in $\mathrm{NaOH}$ by gelatine and some inorganic anions," Corrosion Science, vol. 14, no. 1, pp. 21-24, 1974.

[16] M. Hosseini, S. F. L. Mertens, and M. R. Arshadi, "Synergism and antagonism in mild steel corrosion inhibition by sodium dodecylbenzenesulphonate and hexamethylenetetramine," Corrosion Science, vol. 45, no. 7, pp. 1473-1489, 2003.

[17] X. H. Li and G. N. Mu, “Tween-40 as corrosion inhibitor for cold rolled steel in sulphuric acid: weight loss study, electrochemical characterization, and AFM," Applied Surface Science, vol. 252, no. 5, pp. 1254-1265, 2005.

[18] T. Szauer and A. Brand, "Mechanism of inhibition of electrode reactions at high surface coverages-II," Electrochimica Acta, vol. 26, no. 9, pp. 1219-1224, 1981.

[19] L. Larabi, Y. Harek, M. Traisnel, and A. Mansri, "Synergistic influence of poly(4-vinylpyridine) and potassium iodide on inhibition of corrosion of mild steel in $1 \mathrm{M} \mathrm{HCl}$," Journal of Applied Electrochemistry, vol. 34, no. 8, pp. 833-839, 2004.

[20] X. Li, S. Deng, and H. Fu, "Benzyltrimethylammonium iodide as a corrosion inhibitor for steel in phosphoric acid produced by dihydrate wet method process "' Corrosion Science, vol. 53, no. 5, pp. 664-670, 2011.

[21] C. N. Cao, "On electrochemical techniques for interface inhibitor research," Corrosion Science, vol. 38, no. 12, pp. $2073-$ 2082, 1996.
[22] E. S. Ferreira, C. Giancomelli, F. C. Giacomelli, and A. Spinelli, "Evaluation of the inhibitor effect of 1 -ascorbic acid on the corrosion of mild steel," Materials Chemistry and Physics, vol. 83, no. 1, pp. 129-134, 2004.

[23] S. S. Abdel-Rehim, M. A. M. Ibrahim, and K. F. Khaled, "The inhibition of 4 - $\left(2^{\prime}\right.$-amino- $5^{\prime}$-methylphenylazo $)$ antipyrine on corrosion of mild steel in $\mathrm{HCl}$ solution," Materials Chemistry and Physics, vol. 70, no. 3, pp. 268-273, 2001.

[24] A. K. Singh and M. A. Quraishi, "Effect of Cefazolin on the corrosion of mild steel in $\mathrm{HCl}$ solution," Corrosion Science, vol. 52, no. 1, pp. 152-160, 2010. 


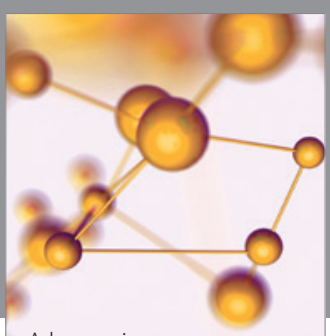

Physical Chemistry
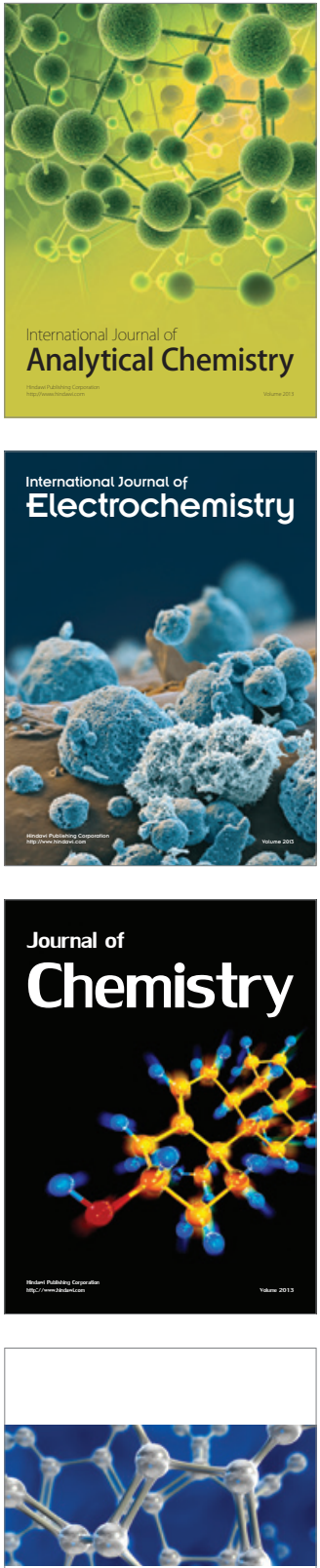

ISRN

Inorganic Chemistry

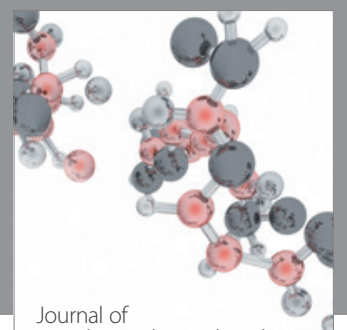

Analytical Methods in Chemistry

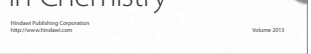

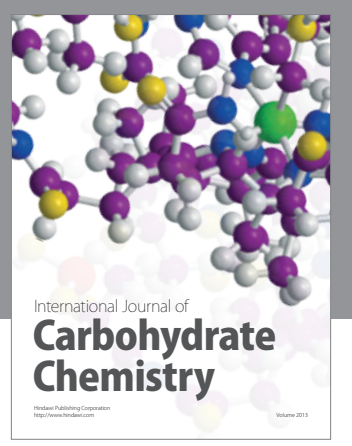
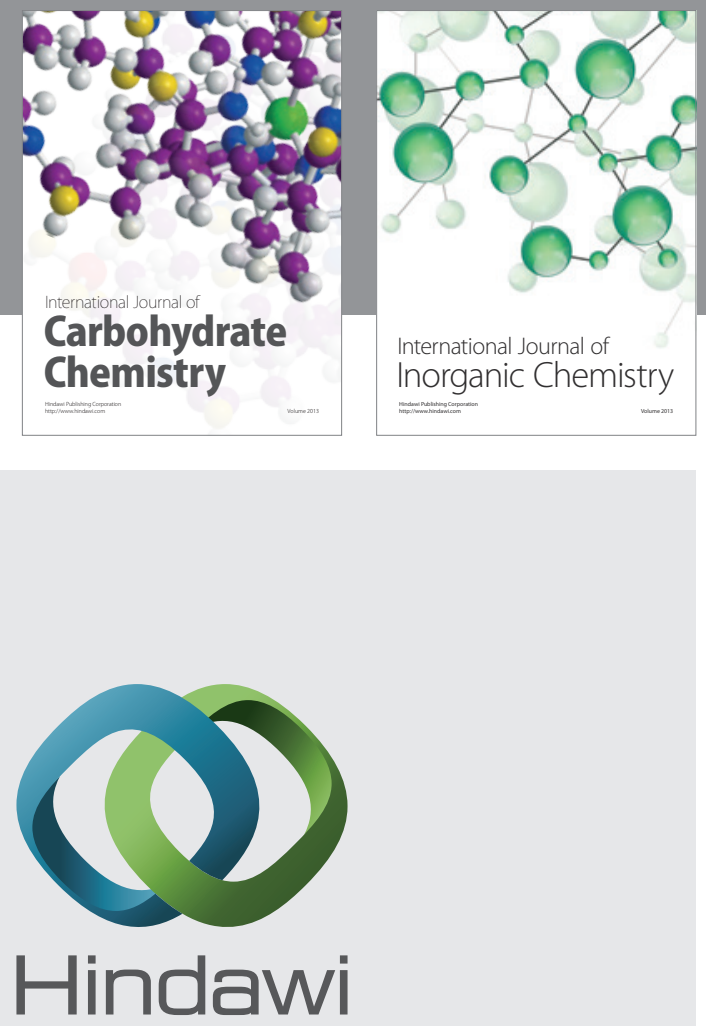

Submit your manuscripts at http://www.hindawi.com
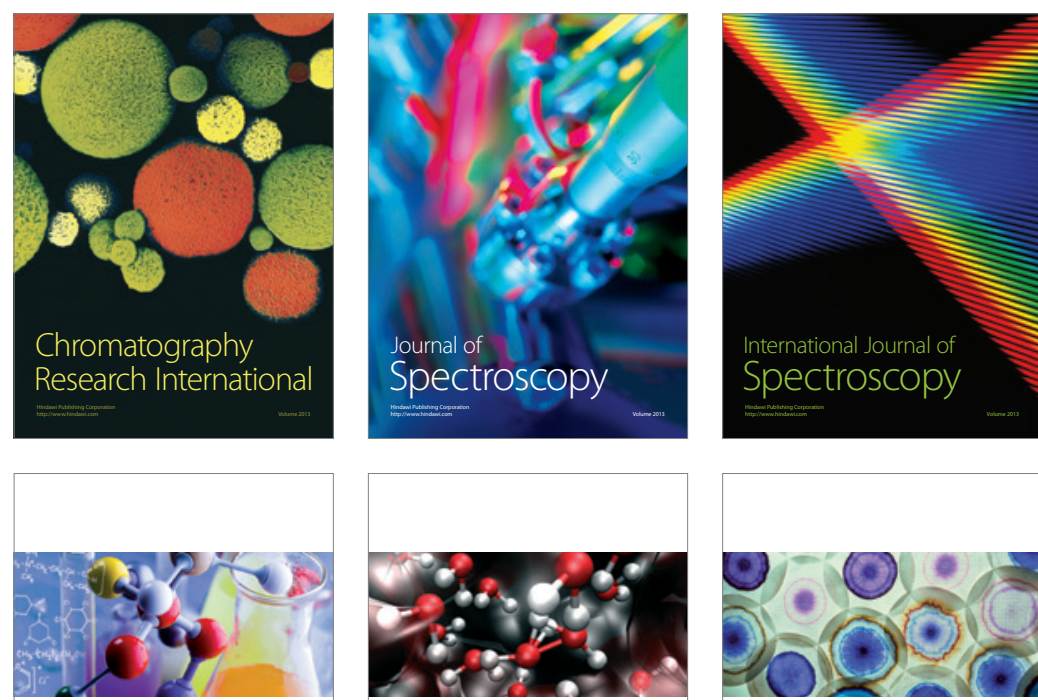

ISRN

ISRN

Organic Chemistry

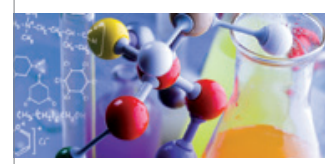

Physical Chemistry

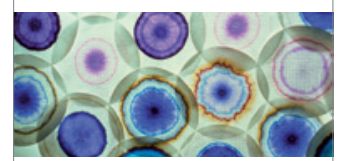

ISRN

Chromatography

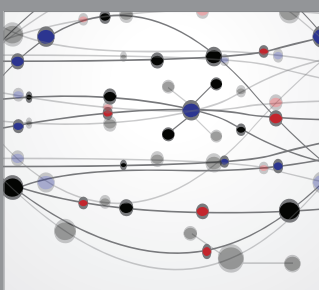

The Scientific World Journal
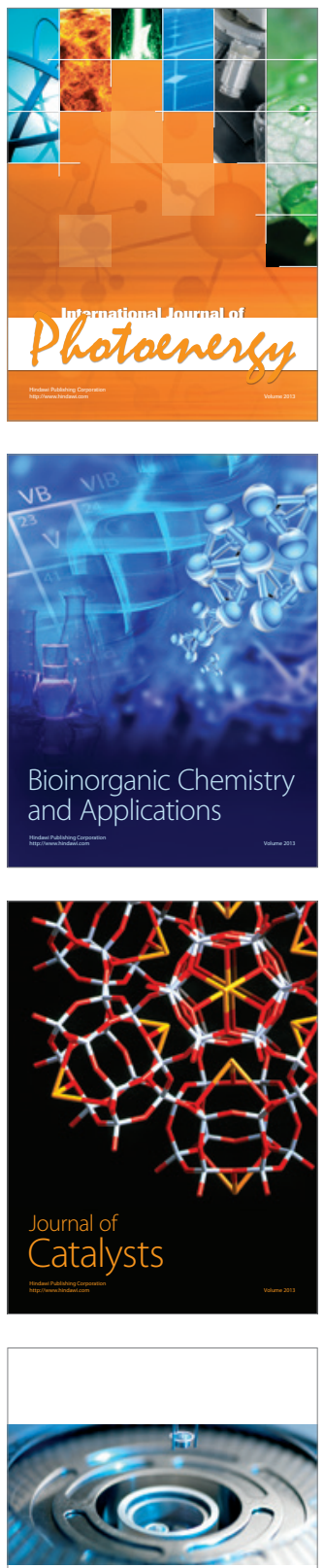

ISRN

Analytical

Chemistry 


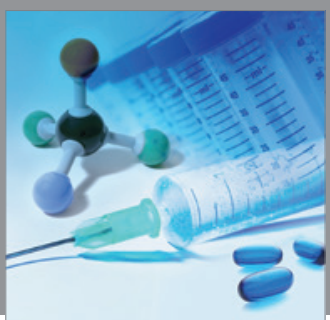

International Journal of

Medicinal Chemistry

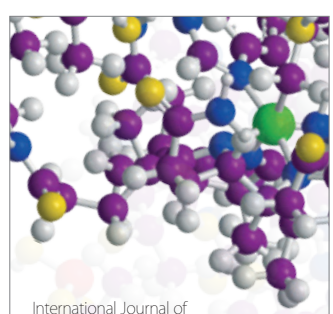

Carbohydrate Chemistry

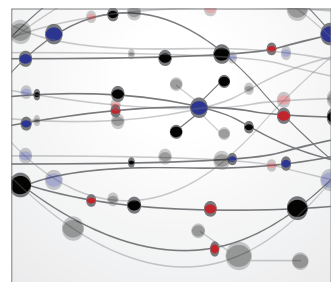

The Scientific World Journal
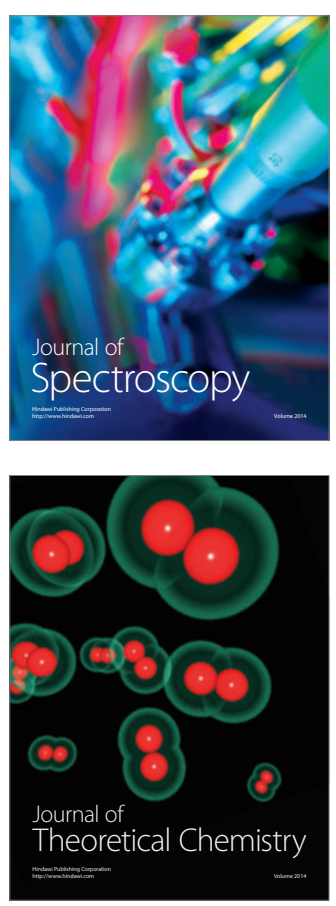
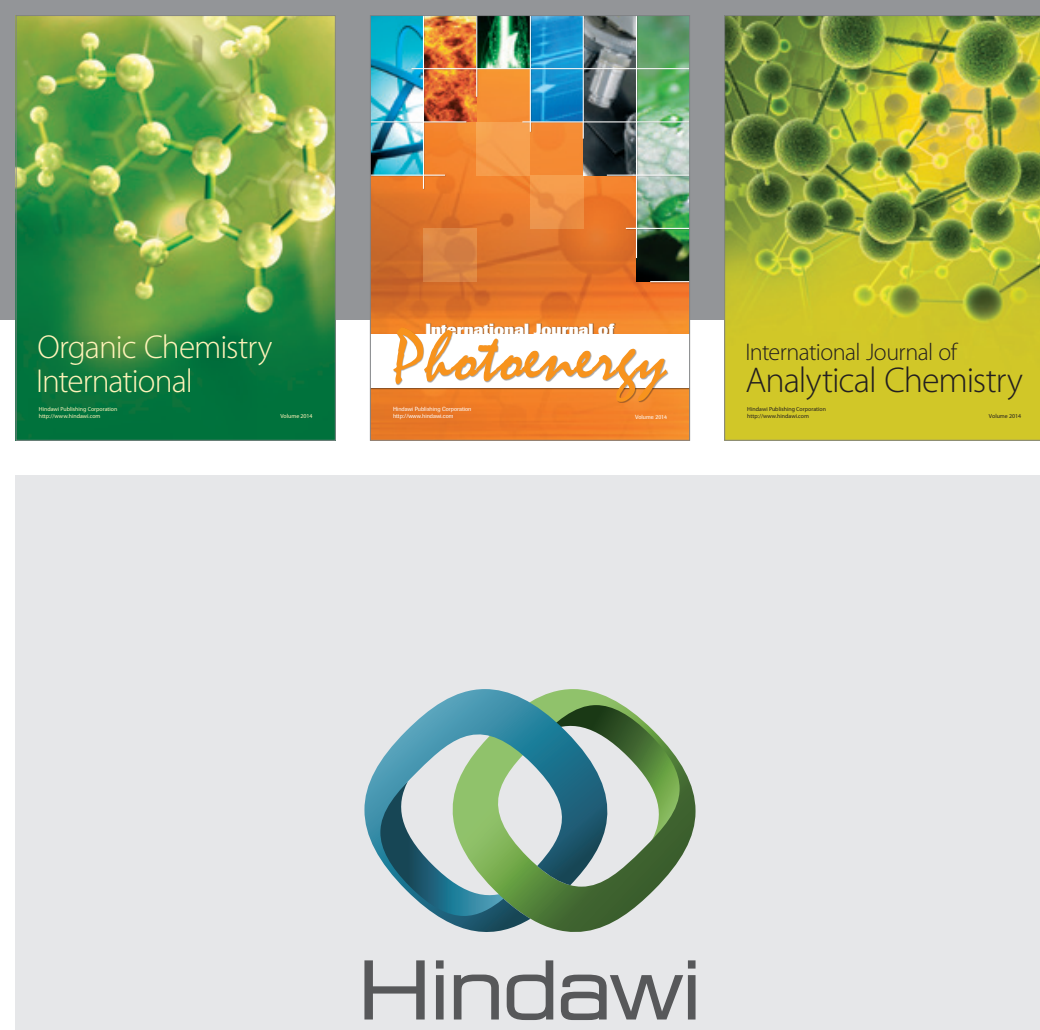

Submit your manuscripts at

http://www.hindawi.com
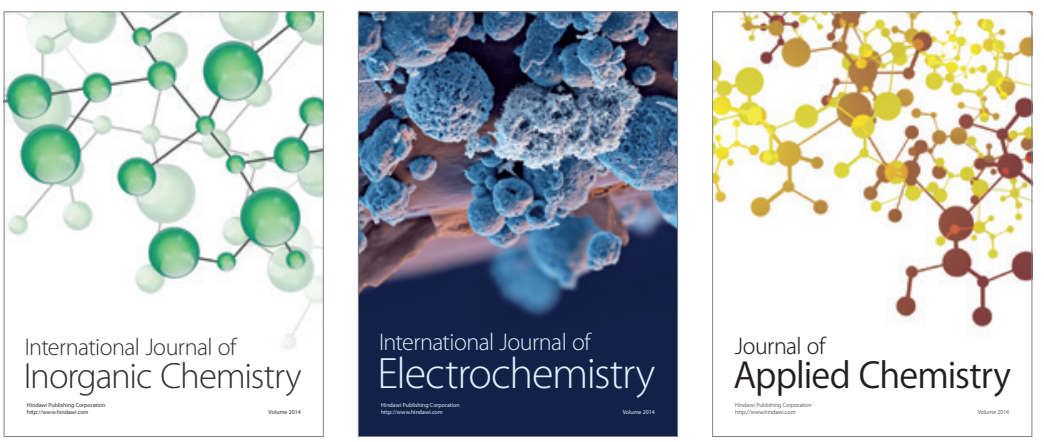

Journal of

Applied Chemistry
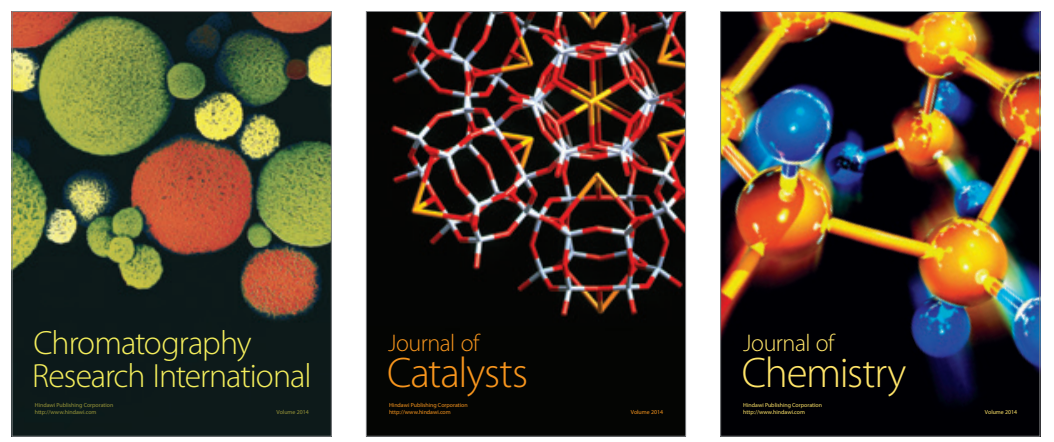
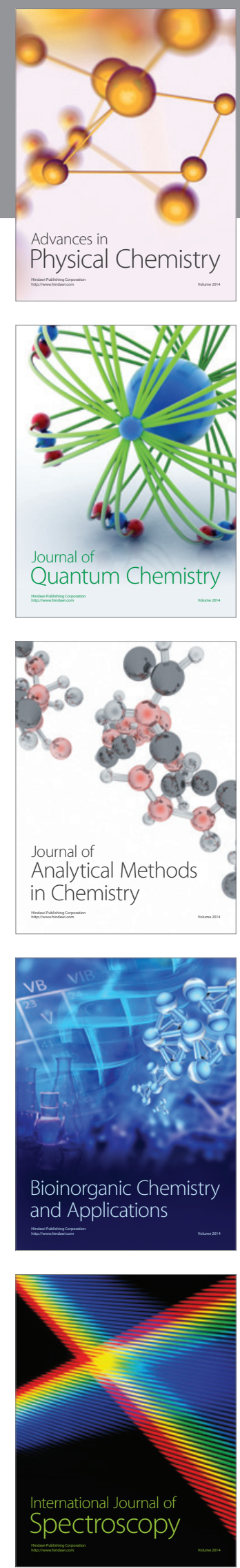